\title{
EDITORIAL
}

\section{The irritable bowel syndrome: soma and psyche ${ }^{1}$}

The diagnosis of the irritable bowel syndrome includes a number of functional bowel disorders presenting with abdominal symptoms without demonstrable organic disease. There is a wide age range at presentation, though the majority of patients are in their second or third decade and twice as many females as males are afflicted (Chaudhary \& Truelove, 1962).

The cardinal symptoms are abdominal pain and distension relieved by defaecation and a change in the frequency or consisténcy of the bowel motion. Abdominal pain is present in $85-90 \%$ of cases and is usually experienced in the lower abdomen and both iliac fossae (Fielding, 1977). Such pain is often postprandial and is relieved by defaecation. A disordered bowel habit is found in $75-90 \%$ of cases and may be continuous or intermittent. Gynaecological and urinary symptoms commonly coexist and most patients admit to symptoms which suggest a functional disorder (Fielding, 1977). The bowel symptoms are also those of colonic organic disease and provide the stimulus for anxiety in both the patient and the doctor (Eastwood \& Nyhlin, 1981; Manning et al. 1981).

Recently, it has been shown that one third of a randomly selected normal population experienced one of four clinically distinct syndromes of functional bowel disorder (Thompson \& Heaton, 1980). Pain was either colonic (in 14\%) or dyspeptic (in 7\%); however, in a further $10 \%$ the syndrome was painless - constipation in $6 \%$ and diarrhoea in $4 \%$. Many subjects who did not have one of these four syndromes had occasional diarrhoea, straining at stool, the passage of pelletty stools, urgency of defaecation, a feeling of incomplete defaecation or abdominal distension.

Studies of gastrointestinal motility during the symptomatic phases of the disorder have shown alterations in motor function of the oesophagus, small bowel and colon which cannot readily be reproduced in the asymptomatic phase (Whorwell et al. 1981; Horowitz \& Farrar, 1962; Wangel \& Deller, 1965). Similar changes in motility can be provoked by gaseous distension of the bowel, by the use of gut hormones - for example, cholecystokinin - and by induced psychological stress (Burns, 1980). Gastrointestinal hormones are known to alter motility but no quantitative hormonal abnormality has been demonstrated in such patients (Harvey, 1977; Besterman et al. 1981). No reliable differences in colonic motility have been found between patients with the irritable bowel syndrome and normal subjects (Ritchie, 1977). Changes in motility may correlate with symptoms and, in some patients, an exaggerated pain response occurs during intestinal contraction (Holdstock et al. 1969).

In the search for an organic cause of the irritable bowel syndrome certain factors have emerged. It is unclear whether these factors are of true aetiological significance or whether they merely cause the patient to seek advice. In one study the symptoms could be traced to an episode of infective gastroenteritis in $25 \%$ of patients (Chaudhary \& Truelove, 1962). In patients living in areas where gastroenteritis is endemic, however, such infections are implicated in only $17 \%$ of irritable bowel states (Bordie, 1972). Since lactose malabsorption causes diarrhoea, flatulence and abdominal distension, intestinal hypolactasia has been extensively investigated. Pena \& Truelove (1972) found hypolactasia in $12 \%$ of irritable bowel patients, a percentage comparable with that of the normal population.

Painter believes that the irritable bowel syndrome is a reflection of the actempt by the normal bowel to cope with chronic dietary fibre depletion and he prefers the term 'irritated bowel syndrome' (Painter, 1972). There are trials of dietary fibre supporting this view, though in general such trials have been poorly designed (Manning et al. 1977; Fielding \& Melvin, 1979). The water holding capacity of wheat bran influences its efficacy and is reduced by cooking or by incorporation into

\footnotetext{
I Address for correspondence: Dr M. A. Eastwood, Gastrointestinal Unit, Western General Hospital, Edinburgh.
} 
biscuits (Robertson \& Eastwood, 1981). Even when bran therapy is apparently effective, pain may persist 2-3 years after investigation and treatment (Nyhlin \& Eastwood, 1981). In addition, studies of the faecal characteristics of patients with the irritable bowel syndrome have shown that the faecal weight, fat and bile acid content failed to differentiate patients from controls (Goy et al. 1976).

Many clinicians have been impressed by the psychological characteristics of patients with the irritable bowel syndrome. Though no attempts have been made to determine cause and effect, it seems likely that the irritable bowel syndrome is often part of and prolonged by psychiatric illness (Young et al. 1976). Symptoms of tiredness, anxiety, depressed mood and sleep disturbance occur in 80-90\% of patients (Chaudhary \& Truelove, 1962; Fielding, 1977). Using structured questionnaires and standardized psychiatric interviews, several workers have established an increased prevalence of psychoneurotic disorders (Palmer et al. 1974; Whitehead et al. 1980; Esler \& Goulston, 1973). Hislop showed a close association with depressive illness and noted a significant improvement in $80 \%$ following treatment with a tricyclic antidepressant (Hislop, 1971). Young et al. (1976) found evidence of a psychiatric illness in $72 \%$ of patients with the irritable bowel syndrome compared with $18 \%$ of a control group.

Stress factors or threatening life events appear to be involved in the production and maintenance of the irritable bowel syndrome. Peters \& Bargen (1944) noted an increased incidence of the irritable bowel syndrome during the second World War which they attributed to stress. Chaudhary \& Truelove (1962) found evidence of psychological stress in over $80 \%$ of their patients, most of it related to marital or domestic disharmony. Mendeloff et al. (1970) compared life events in patients with irritable bowel, inflammatory bowel disease and healthy controls. They showed an excess of bereavement and illness in early life in the irritable bowel group. The irritable bowel patient is at risk of undergoing the removal of a normal appendix (Lane, 1973). In such patients Creed has shown an increase of both threatening life events and psychiatric symptoms compared with patients with an inflamed appendix and a control group (Creed, 1981). Abdominal pain and psychiatric symptoms frequently persisted in the 'normal appendicectomy' group. Current work on threatening life events in patients with the irritable bowel syndrome seems likely to show a similar clustering of events in the months preceding the presentation or relapse of the condition.

The irritable bowel syndrome is a cluster of symptoms which reflect the limited repertoire of the gut's responses. Three main areas have emerged in the aetiology: namely, organic disease (including dietary fibre deficiency), psychiatric constitution, and life events. The variable interplay between these three factors may be defined using a ternary phase model. The shape of this triangle will vary between individuals and within an individual at different times. The definition of the irritable bowel syndrome as a disease is unhelpful and the clinician must identify the influence of each of the three elements in his patients. To soma and psyche must be added circumstances.

\section{J. FORD, JENNY EASTWOOD AND M. A. EASTWOOD}

\section{REFERENCES}

Besterman, H. S., Sarson, D. L., Rambaud. J. C., Stewart. J. S., Guerin, S. \& Bloom, S. R. (1981). Gut hormone responses in the irritable bowel syndrome. Digestion 21, 219-224.

Bordie, A. K. (1972). Functional disorders of the colon. Journal of the Indian Medical Association 58, 451 -456.

Burns. T. W. (1980). Colonic motility in the irritable bowel syndrome. Archives of Internal Medicine 140, 247251.

Chaudhary, N.A. \& Truelove, S. C. (1962). The irritable colon syndrome. A study of the clinical features, predisposing causes and prognosis in 130 cases. Quarterly Journal of Medicine 31. 307-322.

Creed, F. (1981). Life events and appendicectomy. Lancet ii, 13811385.

Eastwood, M. A. \& Nyhlin, H. (1981). Irritable bowel syndrome. Gastroenterology 80, 633(c).

Esler, M. D. \& Goulston, K. J. (1973). Levels of anxiety in colonic disorders. New' England Journal of Medicine 288, 1620.
Fielding, J. F. (1977). The irritable bowel syndrome: the clinical spectrum. Clinics in Gastroenterology 6 (3), 607622.

Fielding, J. F. \& Melvin, K. (1979). Dietary fibre and the irritable bowel syndrome. Journal of Human Nurrition 33, 243247.

Goy, J. A. E., Eastwood, M. A., Mitchell, W. D., Pritchard, J. L. \& Smith, A. N. (1976). Faecal characteristics contrasted in the irritable bowel syndrome and diverticular disease. American Journal of Clinical Nutrition 29, $1480-1484$.

Harvey, R. F. (1977). The irritable bowel syndrome. Hormonal influences. Clinics in Gastroenterology' 6 (3), 631 641.

Hislop, I. G. (1971). Psychological significance of the irritable colon syndrome. Gut 12, 452-457.

Holdstock, D. J., Misiewicz, J. J. \& Waller, S. L. (1969). Observations on the mechanism of abdominal pain. Gut 10, 1931 .

Horowitz, L. \& Farrar, J. T. (1962). Intraluminal small intestinal pressures in normal patients and in patients with functional gastrointestinal disorders. Gastroenterology 42, 455464 
Lane. D. (1973). The irritable colon and right iliac fossa pain. Medical Journal of Australia i, 66-67.

Manning. A. P., Heaton. K. W.. Harvey. R. F. \& Uglow. P. (1977). Wheat fibre and irritable bowel syndrome. Lancet ii, 417418 .

Manning, A. P.. Thompson, W. G., Heaton, K. W. \& Morris, A. F. (1978). Towards positive diagnosis of the irritable bowel. British Medical Journal ii. 653654

Mendelofi, A. I., Monk, M., Siegel, C. I. \& Lilienfield. A. (1970). Illness experience and life stresses in patients with irritable colon and with ulcerative colitis. New England Journal of Medicine 282. 1417.

Nyhlin, H. \& Eastwood. M. A. (1981). Comparison of various treatments for irritable bowel syndrome. British Medical Journal 282. 74 75(c).

Painter, N. S. (1972). Irritable or irritated bowel. British Medical Journal ii, 46(c).

Palmer, R. L.. Stonehill, E.. Crisp, A. H, Waller, S. L. \& Misiewicz. J. J. (1974). Psychological characteristics of patients with the irritable bowel syndrome. Postgraduate Medical Journal 50. 416-419.

Pena, A. S. \& Truelove, S. C. (1972). Hypolactasia and the irritable colon syndrome. Scandinavian Journal of Gastroenterology 7. 433438

Peters. G. A. \& Bargen, J. A. (1944). The irritable bowel syndrome. Gastroenterology 3, $399-402$.
Ritchie, J. (1977). The irrilable bowel syndrome. Manometric and cineradiographic studies. Clinics in Gastroenterolog 1 6(3).622 631 .

Robertson, J. A. \& Eastwood. M. A. (1981). An examination of factors which may affect the water-holding capacity of dietary fibre. British Journal of Nutrition 45, 8387.

Thompson, W. G. \& Heaton, K. W. (1980). Functional bowel disorders in apparently healthy people. Gastroenterology 79. 283288.

Wangel, A. G. \& Deller, D. J. (1965). Intestinal motility in man. Mechanisms of constipation and diarrhoea with particular reference to the irritable colon syndrome. Gastroenterology' 48 . 69.84.

Whitehead, W. E., Engel, B. T. \& Schuster, M. M. (1980). Irritable bowel syndrome. Physiological and psychological differences between diarrhoea-predominant and constipation-predominant patients. Digestive Diseases and Sciences 25, 404-413.

Whorwell, P. J., Clouter, C. \& Smith. C. L. (1981). Uesophageal motility in the irritable bowel syndrome. British Medical Journal 282, $1101-1102$.

Young, S. J., Alpers, D. H., Norland, C. C. \& Woodruff, R. A. (1976). Psychiatric illness and the irritable bowel syndrome. Practical implications for the primary physician. Gastroenterology 70, $162-166$ 